William Gowers. He states ${ }^{2}$ that the diabetic neuritis is not related to the amount of sugar in the urine and that it is not readily influenced by a dietetic reduction of the amount of sugar in the blood. I quite agree with the second part of this assertion but I believe that in its onset true diabetic meuritis is very often, if not always, closely related to the amount of sugar present. Very of ten the amount of fugar excreted was very great when the neuritis began, either because the patient had neglected his diet or because he was unaware of his having diabetes and so involuntarily, keeping up a great amount of sugar. The amount of sugar present at the time when the neuritis began or shortly before in the 11 cases given above was in Case 1, 3.6 per cent.; in Case $2,4.1$ per cont. ; in Case 3,23 per cent.; in Case 4,6 0 per cent. ; in Case 5, 4.8 per cent. ; in Case 6,27 per cent.; in Case $7,2.5$ per cent. ; in Case $8,4.5$ per cent.; in Case $9,4.3$ per cent.; in Case 10 , 05 per cent.; and in Case $11,6.0$ per cent. The only case in which the amount of sugar was small was Case 10, and in this case it is doubtful whether abuse of alcohol bad not been of great influence in producing the neuritis.

According to my observations a great amount of sugar is generally present in the beginning of diabetic neuritis, but when the inflammation is once started it runs its own course independently and without being apparently influenced by the dietetic treatment. That the amount of sugar circulating in the blood actually has an influence on the nerves is shown by the frequent occurrence of cramps, especially in the legs of diabetic patients. These cramps are an almost constant symptom of early diabetes - that is to say, when the amount of sugar present is great. They soon disappear when the amount of sugar has been reduced, but are apt to recur when there is again an increase. They seem, therefore, to be solely produced by the sugar circulating in the blood

We have, therefore, three manifestations of nervous disturbance caused by the increase of the sugar in the blood: (1) cramps or an acute irritation of nerves, probably not accompanied by any material change in the nerves; (2) neuritis or acute inflammation of the nerves; and (3) a slow degeneration or nutritive change in the nerves which seems to have a preference for the crural nerve and is then accompanied by loss of the knee-jerks, but which may also occur in other nerves, as, for instance, in the optic nerve. It then leads to a gradual diminution of vision with central scotoma. The impotence which is so frequently a symptom in male diabetic subjects is also probably caused by nutritive changes in the corresponding nervous apparatus. I bave frequently found it to be associated with loss of the knee-jerks.

Neuenahr, Germany.

\section{TWO RECENT CASES OF SUCCESSFUL OPERATION FOR IMPACTED STONE IN THE URETER. ${ }^{1}$}

Br P. J. FREYER, M.A., M.D., M.CH., SURGEON TO ST. PETER'S HOSPITAL FOR STONE, ETC.

THE short paper to which I invite your attention this evening is to be regarded as a mere fragment-a brief contribution to the surgery of the ureter. This is a subject which during the last few years has engaged the attention of surgeons, and still how few instances of operation for stone in the ureter have been placed on record. I think you will agree with me that it is incumbent on every surgeon who meets with such cases in his practice to publish details of them so that in time we may have accumulated a sufficiently large and varied number of cases as a basis from which to draw authoritative conclusions as to the best methods of dealing with stone impacted in any particular part of the ureteral canal. It is in this spirit that I venture to place before you details of two cases of operation for impacted ureteral calculus which have recently fallen to my lot, each in its way, I venture to think, possessing some features of interest.

CASE 1.-An officer, aged 23 years, who was sent to me by Dr. Charles Blood of Woolwich, consulted me on July 19th,

2 Manual of Diseases of the Nervous System, second edition, vol. i., p 116

${ }^{1}$ A paper read before meeting of the Nedical Society of London on Jan. 23rd, 1899.
1898. He had suffered off and on for 19 months from renal colic and homaturia. The symptoms first set in at Malta in January, 1897, in the form of colicky pains in both loins, extending across the abdomen, whenever he rode on horseback. These were at first considered to be due to indigestion; but on the third or fourth day on dismounting from his horse he found that his urine contained blood and he thercfore went on the sick list. The symptoms passed off in a few days with rest and treatment. Three weeks later, his duties being henvy and involving much riding, the symptoms returned and he har again to go on the sick list. The pain at this period was mainly contined to the left side, commencing in the loin and sbooting down to the groin and some im is across the abdomen, and giving rise to the sensalion of a string being tied tightly round the body. At no period did the pain shoot down into the testicle nor was this organ retracted. The symptoms continuing he came to England in May, 1897, and placed himself ut der the care of a well-known London physician. The renal attacks with hrematuria continued to come on periodically every fortnight or so, and, strange to say, two of his worst attacks seemed to bave bcen brought on by short sailing trips, though he did not suffer from sea-sickness. Getting no better he returned to Malta in August and during the voyage painless hrematuria set in, which continued off and on till September when another severe attack of pain in the left loin occurred and the hamaturia suddenly ceased. He was then seen by Major L. W. Swabey, R.A.M.C., who diagnosed the case as one of stone in the kidney. Being unable to continue at duty he went to Sicily, but the voyage again brought on hrematuria accompanied by fever which after lasting a week again wound up with severe colic. He returned to duty at Malta at the end of October, but in order to relieve the pain be had to lie down for several hours in the middle of the day. The re-drilling commenced on Nov. 1st and the first routemarch brought on pain and hemorrhage. He was therefore excused marching and rode in a caniage, but though the pain was less the hæmorrhage continued. In December he passed two stones by the uretbra; they were cylindrical in shape and like red sandstone. The acute pain up to this time was in the left side, and from that period until July, 1898, though there was occasional hæmaturia and the urice contained albumin, there was no severe pain but merely a dull aching in both loins. In May, 1898, he returned to England for duty at Woolwich. On July 10th he took much exercise and on the next day an acute attack of pain set in in the right side which lasted 72 hours continuously, during which he was kept under the influence of morphia by Dr. Blood. The pain was excruciating, accompanied by restlessness, nausea, and vomiting, with a constant desire to micturate, but only a small quantity of high-coloured urine passed on each occasion. For two days after this attack the urine was clear, but it became thick and bloody again. I found that there was a slightly moveable tumour as large as two fists in the region of the right kidney which was extremely tender on palpation both in the loin and in front. There was no stabbing pain on pressure at the back, but there was distinct tenderness at ore spot in front midway between the navel and the anterior superior spine of the ilium. The urine had the colour of Madeira wine; it was acid, of the specific gravity of 1015 , and it contained bloodcorpuscles and crystals of oxalate of lime and also albumin The left kidney was normal. I diagnosed the case as one of stone in the pelvis of the kidney trying to pass down the ureter and causing obstruction of urine.

On July 30th the patient entered a surgical home and on August 1st I operated, Mr. F. W. Braine giving the anæsthetic and Mr. B. Smeaton assisting. Dr. M. A. MacDonnell, M.P., and Dr. H. T. Griffiths were also present. The kidney was rapidly exposed through an oblique lumbar incision four and a half inches long and the fatty capsule was opened. On feeling it all over no stone was detected. The kidney, which was much enlarged and congested, was stripped of its fatty capsule and brought on to the loin through the wound. I felt it carefully all over but could detect no stone. The kidney was then opened through the convex border by means of a scalpel, and my finger was passed into the pelvis, a rush of urine taking place tlirough the wound and the kidney collapsing much in size. No stone could be found, though my finger passed easily into the calyces, which with the pelvis formed a large smooth-walled cavity. I then passed a catheter down the ureter as far as four inches from the pelvis where it was obstructed. A long 
silver probe was then passed and a stone was felt in the areter at this point. The incision in the loin was at once extended downwards and inwards for four or five inches, and the peritoneum was raised inwards from off the ureter by my fingers until I could grasp the stone-which felt of the size of a filbert-lying in the ureter between my finger and thumb. I made several attempts to push the stone upwards into the kidney, but it was too firmly impacted in the ureter. The ureter was therefore incised longitudinally over the stone, which was pushed through the wound by the point of $\mathrm{my}$ finger. A bougie was then passed into the bladder from the pelvis through the ureter. I did not suture the wound in the ureter because (1) the suturing of the ureter when a stone is removed extra-peritoneally is a debateable proceeding; (2) because the ureter was so narrow that suturing would probably have caused contraction of the canal; and (3) because, though I could extract the stone with the limited incision already indicated, the successful suturing of the wreter at the bottom of a deep wound was impossible without a much more extended dissection. I contented myself, therefore, by placing a large drainagetube down to the opening in the ureter along the back of the kidney, bringing the muscles together by buried silk sutures and the superficial parts by silkworm gut. The wound in the kidney was partially closed by two sutures, the middle portion being left open so that urine might flow freely through the loin and thus avoid tension on the ureter till the wound in it should have healed. Bloody urine was passed freely by the urethra in the evening, showing that the ureter was patent, and bloody urine by both loin and urethra for several days. On the third day I began to shorten the drainage-tube daily, and this was completely removed on August 7th. On the 8th the wound was firmly united save in the track of the drainage-tube, and on the 9 th urine ceased to flow by the loin. The patient made a rapid recovery. He was sitting up on Angust 28th, he went for a walk on Sept. 2nd, and he left the Home on Sept. 7th, travelling by train to Margate. Soon afterwards he began to ride a bicycle and he started to resume duty at Gibraltar on Nov. 15th. He is now in excellent health and he wrote to me at the end of December, 1898 , that he did five or six hours' work daily and for that purpose ascended the Rock for 1300 feet.

It may be of interest to mention, as bearing on the hereditary tendency of stone, that owing to the successful result in this case the patient's mother, who for 17 years had suffered from stone in the kidney, placed herself in my hands. On Sept. 28th, 1898, I performed a lumbar nephrolithotomy. Dr. Dudley Buxton acted as anrsthetist, and Mr. Swinford Edwards assisted me. A somewhat large oxalate of lime stone was removed from the pelvis and several smaller ones were remored from the calyces. The kidney, which was extremely large, was sutured. No urine passed by the wound and the patient made a rapid and successful recovery. Furthermore, this lady's father suffered severely from gravel for several years before his death. Some years ago I operated successfulty for stone in the bladder during the same year on the representatives of three generations--viz., son, father, and grandfather.

CASE 2.-A man, aged 53 years, had been a patient at St. Peter's Hospital for Stone off and on for 13 years suffering from multiple stricture of the urethra, which had been operated on several times, and from symptoms of kidney stone. In 1895 bis left kidney was explored for stone by another surgeon but with a negative result. Temporary relief ensued, but the old symptoms again returned and in the summer of 1897 be was very ill, the pain in the left loin being very severe, at times radiating to the groin and testicle and accompanied by hæmaturia which at times was very profuse. There was also occasional pain in the right loin. The arine was extremely thick and offensive and on standing it deposited about half pus. Under these circumstances I determined to explore the left kidney again and this was accomplished on Sept. 1st, 1897, by an oblique lumbar incision. A most careful search was made, but no kidney was found, though I passed my fingers well up under the ribs, down to the iliac fossa, and inwards to the aorta, pushing the peritoneum out of the way. The patient rapidly recovered from the operation, but there was only a very temporary relief of the symptoms, which soon set in again as badly as ever. Under the impression that the symptoms might in a large measure be dne to backward pressure resulting from the stricture, which had again contracted so that a No. 6 bougie (Knglish scale) was passed with difficalty,
I performed internal urethrotomy on Nov. 18th, cutting three dense cartilaginous strictures up to 16 of the English scale. For two days after the operation the patient was extremely ill with severe rigors, the temperature rising to $106^{\circ} \mathrm{F}$. and the urine being very scanty, but he slowly recovered, leaving the hospital early in January, 1898. This operation, though it afforded a free flow for the passage of the urine, did not much diminish the other symptoms. Though the pain in the left loin gradually diminished that in the right loin increased, and for months the patient continued to attend the out-patient elepartment, his urine constantly containing much pus and at times a considerable quantity of blood. Occasionally the right loin became much swollen and the disappearance of the swelling was always followed by an increase in the quantity of pus in the urine. In October he began to complain of great irritability of the bladder and there was a constant desire to pass water with pain at the end of the penis. He was again admitted into the hospital and on Nov. 9th made a cystoscopic examination under an anæsthetic and detected a long, narrow, rough, pencil-shaped stone, projecting into the bladder from the right uretera. opening. The portion of stone projecting into the bladder appeared by the cystoscope to be about three-quarters of an inch long, and dark grey in colour. My colleague Mr. Reginald Harrison, and others had an excellent view of the stone. I at once introduced a lithotrite and, after three or four unsuccessful attempts, eventually caught the stone between the blades, pulled it out of the ureteral opening, crushed it, and removed the débris, which consisted of urates and weighed 12 grains, by the aspirator. On Nov. 23rd the patient again underwent a cystoscopic examination. The bladder walls were coated with mucus; both ureters were seen to be acting and flakes of pus to be issuing from them. The patient has continued to improve steadily in health. The pains in the loins have disappeared; there is no hrematuria and scarcely any pus in his urine. He states that he is in better health than he has been for years.

The history of this case presents many points for specula. tion which would, however, be foreign to the purpose of this paper, the case being now brought forward merely for the purpose of illustrating what $I$ believe to be a novel method by which a stone projecting from the ureteral orifice into the bladder may possibly sometimes be removed.

I will, in conclusion, briefly refer to five other instances of stone impacted or encysted in the ureter which have been operated upon by me, four of them during my experience in India. In three of these cases the stone was impacted at. the ureteral orifice, projecting into the bladder and was felt by the sound. One of them occurred in a female and two of them in males. In each instance an operation was undertaken under the impression that I had to deal with as ordinary case of stone in the bladder, and in each the stone was dislodged from its position by introducing the forefinger through the dilated urethra in the female and through the ordinary perineal lithotomy wound in the males, scraping the orifice of the ureter with the finger-nail, the stone being forced downwards and inwards by the hand placed on the groin and then removed with the ordinary lithotomy forceps. I have published details of a case ${ }^{2}$ in which I removed by litholapaxy from a boy, aged 15 years, at two different sittings two separate stones, weighing respectively 767 grains and 681 grains, aggregating more than three and a quarter ounces. After removing the first stone from the bladder I found that there was a second one lying in the lower part of the right ureter close to the bladder. The second stone was felt as a hard tumour about three inches long in the loin and could be easily felt in the ureter between a finger inserted in the rectum and the band placed on the groin. I determined to remove the stone by a suprapubic cystotomy as soon as the patient should have recovered from the first operation, but on the fourth day the tumour in the groin suddenly disappeared and a stone was felt lying free in the bladder and was successfully disposed of by litholapaxy. Evidently this latter stone lying in the ureter rested on the stone located in the bladder. As soon as this support was removed the ureteral calculus was pushed on into the bladder by the force of the accumulated urine behind it. The fifth case ${ }^{3}$ was that of an obscure cystic tumour of the bladder which contained two calculi weighing 
41 grains, which was removed suprapubically. My explanation of the case was this: that the stones descending from the kidney were arrested at that portion of the ureter which passes obliquely through the bladder wall, and that, unable to escape owing to a contracted orifice, they bulged the bladder wall inwards, forming a smooth cystic tumour which was recognised by the aid of the cystoscope and succossfully dealt with in the way which I have indicated.

Harley-street, $W$.

\section{A CASE OF TRAUMATIC EPILEPSY FOL- LOWING A COMPOUND FRACTURE OF THE SKULL SUSTAINED ELEVEN YEARS PREVIOUSLY;}

REMOFAL OF ADHERENT CICATRIX AND CLOSURE OF THE OPENING IN THE SKULL BY A SILVER PLATE; RECOVERY.1

Bx PHILIP JAMES, F.R.C.S. ENG.

THE case which I am about to relate is, I think, deserving of record from two points of view. It is, I believe, the first case in which the hetero-plastic method for the repair of fractures of the skull has been adopted in these colonies; indeed, at the time I thought I was breaking new ground altogether, but some months later $I$ read that Professor Willy Meyer of New York had already published a case. ${ }^{2}$ That case, however, which was published in the Annals of Surgery for March, 1895, does not appear to be quite on all fours with mine. In Professor Willy Meyer's case the brain protruded so that the dura mater could not be drawn over it and the plate was obviously employed to prevent a hernia cerebri. In my case a plate was used to prevent a recurrence of adhesions. But however interesting from a surgical standpoint it is, in my opinion, of even greater importance as bearing upon the obscure subject of cerebral physiology and pathology. In June, 1895, Dr. (now Sir) W. R. Gowers, in the Bowman Lecture delivered before the Ophthalmological Society of the United Kingdom, discoursed very eloquently upon some of the subjective visual spectra of epilepsy and migraine. ${ }^{3}$ I would strongly advise those who are interested in this subject to study this most interesting lecture. As its title indicates Sir W. R. Gowers's conclusions are drawn from subjective evidence alone and I think you will agree with me that this case furnishes valuable objective proof that those conclusions are correct. With a view to make the facts of the case reliable I made before operating careful surface markings according to Reid's method and so I am able to record the exact relation of the cicatrix to the subjacent cerebral structures.

A man, aged 24 years, came to consult me on Oct. 10th, 1895, suffering from epileptic fits which had developed during the year then current and which he attributed to an injury to the head received 10 or 11 years previously. He was a bealthy-looking, fairly muscular young man who had always enjoyer robust health. When he was between 13 and 14 vears of age he sustained a compound fracture of the skull. He made a good recovery and remained well until January, 1895, when he had an epileptic fit. The first attack occurred when he was getting up in the morning and he was unconscious for an hour. Three months later he had another, also when he was getting up, and he was again unconscious for an hour. The third fit came on when he was in bed asleep and the first he knew of it wds when sitting at the fireside and asking his mate how he got there, when he was told that he had had a fit. The fourth attack also came on at about 5 A.M. He was awake and felt it coming on. The fits were about equal in severity, but since the last one he had been losing flesh and strength. He recognised the advent of the fits by his beginning to tremble all over. His heart would beat very quickly and his breathing would become "heavy." There were no jerkings of the arms or the legs-that is, in the premonitory stage.

1 A paper read before the New Zealand Branch of the British Medica Association at Nelson.

2 Year-book of Treatment, 1886

3 THE LAXCET, June 22nd and 29th, 1895.
His sight would become dim, until finally before losing con sciousness everything would have become dark around him. He never saw streaks of light or stars. He had never had fits before the injury and no other member of his family had ever suffered from fits of any kind. There was no history of tubercle or of syphilis. The dimness of vision occasionally occurred without a fit supervening. The cicatrix in the scalp measured about four and a balf inches in length; it was situated on the right side of the vertex of the skull and extended from near the median line

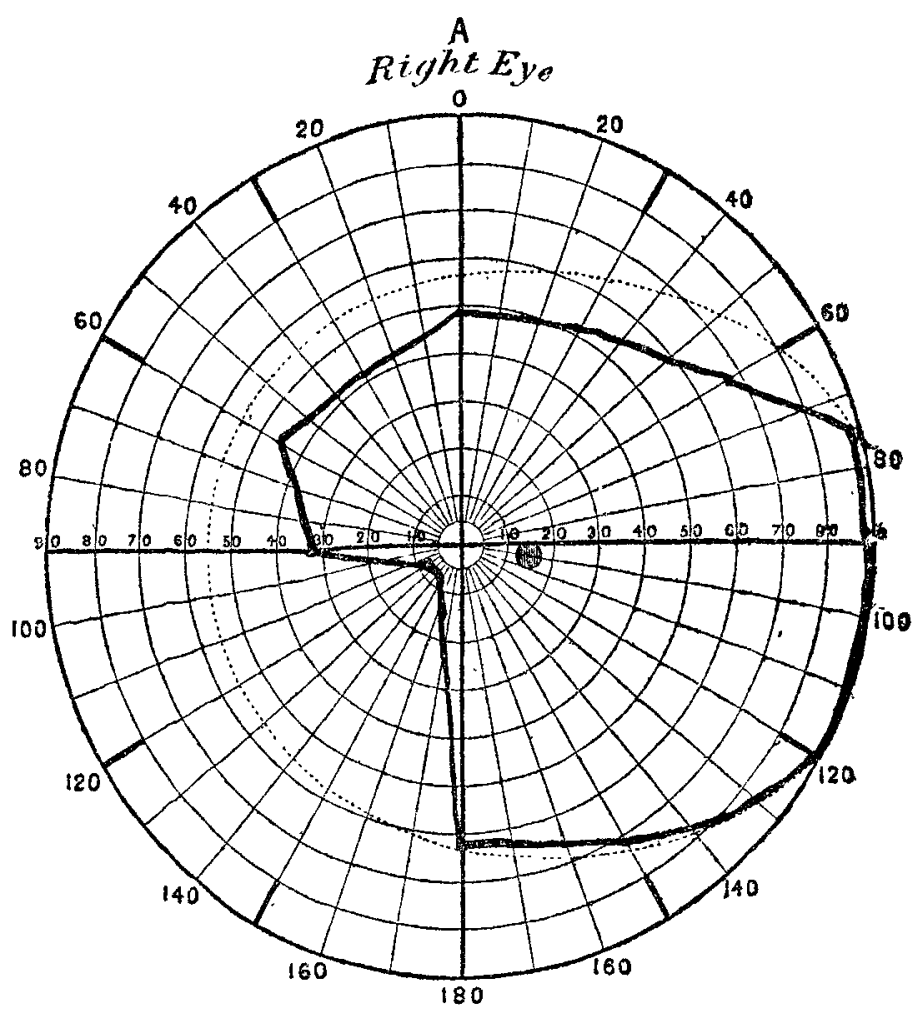

Perimeter chart of right eye.

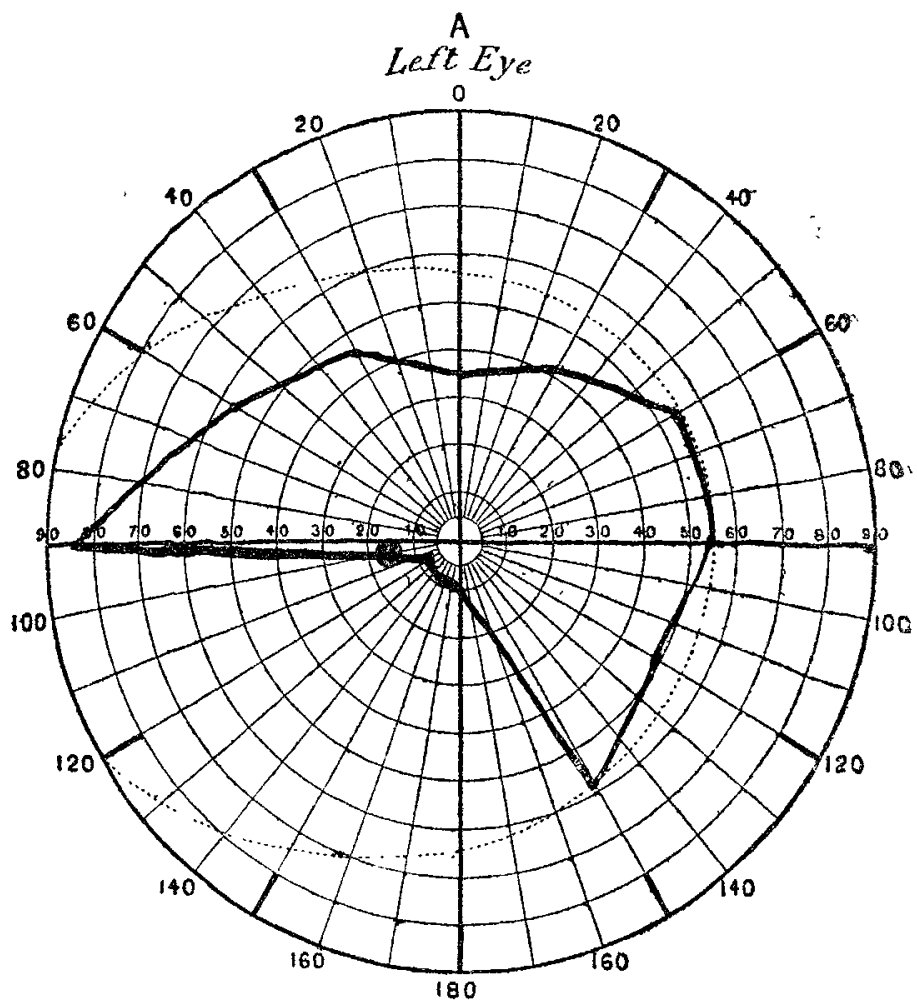

Perimeter chart of left eye

in a direction outwards and backwards. The scar wa considerably depressed anteriorly and posteriorly. Abou its middle it was divided into two parts by a bridge o apparently unfractured bone. Both in front of and behin this bridge there was loss of bone and posteriorly th pulsation of the brain was plainly to be seen. Anterior the cerebral pulsations could not be detected, but imme diately in front of the bony bridge there was a spot, pressur on which caused great pain, trembling, and dimness sight-symptoms which, he declared, were identical wit those which preceded a fit. The position of the fissure 0 